\title{
DISSIMILARIDADE GENÉTICA EM MUTANTES DE AVEIA TOLERANTES E SENSÍVEIS A ÁCIDOS ORGÂNICOS ${ }^{(1)}$
}

\author{
VELCIQUEIROZ DE SOUZA ${ }^{(2)}$; ARIONE DA SILVA PEREIRA ${ }^{(3)}$; MAURICIO MARINI KOPP(2); \\ JEFFERSON LUIZ MEIRELLES COIMBRA ${ }^{(2)}$; FERNANDO IRAJÁ FÉLIX DE CARVALHO ${ }^{(4)}$; \\ VIVIANE KOPP DA LUZ ${ }^{(5)}$; ANTÔNIO COSTA DE OLIVEIRA ${ }^{(4)}$
}

\begin{abstract}
RESUMO
Para que o cultivo da aveia (Avena sativa L.) seja também alternativa economicamente viável em solos de várzea, faz-se necessário a utilização de cultivares tolerantes aos principais ácidos orgânicos produzidos pela decomposição da matéria orgânica gerada em cultivos com plantio direto. Este trabalho objetivou determinar a dissimilaridade genética entre famílias mutantes $\mathrm{M}_{3}$ e a cultivar UFRGS 14 de aveia mediante a utilização de marcadores ISSR, e detectar regiões genômicas associadas ao caráter tolerância a ácidos orgânicos. Foram avaliadas 30 famílias mutantes $\left(\mathrm{M}_{3}\right)$, pertencentes ao banco de mutantes de aveia do Centro de Genômica e Fitomelhoramento da Faculdade de Agronomia "Eliseu Maciel". As famílias estudadas foram originadas da cultivar UFRGS 14 irradiada com raios gama $\left(\mathrm{Co}^{60}\right)$ na dose de 400 Gy. A caracterização genética foi realizada utilizando-se a técnica de marcadores ISSR. Pelos resultados verifica-se que os oligonucleotídeos UBC 854, 855, e 811 permitiram detectar regiões genômicas relacionadas à tolerância à toxicidade por ácidos orgânicos, enquanto os oligonucleotídeos UBC 850 e 826 possibilitaram identificar regiões genômicas associadas à sensibilidade.
\end{abstract}

Palavras-chave: marcadores moleculares; marcadores ISSR; raios gama $\left(\mathrm{Co}^{60}\right)$.

\author{
ABSTRACT \\ GENETIC DISSIMILARITY IN OAT (AVENA SATIVA L.) TOLERANT AND SENSITIVE \\ MUTANTS TO ORGANIC ACIDS
}

In order to cultivate oats (Avena sativa L.) as an economically alternative in low lands, it is necessary to use cultivars tolerant to the main organic acids produced by organic matter decomposition resulting from no tillage systems. The objectives of this work were estimate genetic dissimilarity among $\mathrm{M}_{3}$ mutant families and the oat cultivar UFRGS 14 using ISSR markers; and to detect genomic regions associated with organic acids toxicity. Thirty $\mathrm{M}_{3}$ mutant families from the Plant Genomic Center of the College of Agronomy "Eliseu Maciel", derived from the cultivar UFRGS 14 irradiated with gamma ray $\left(\mathrm{Co}^{60}\right)$ at 400 Gy dosage were used. The genetic characterization was carried out using the ISSR marker technique. The results indicated that UBC 854, 855 and 811 primers allowed the identification of genomic regions related to organic acid toxicity tolerance, while UBC 850 and 826 primers of genomic regions associated to organic acid sensitivity.

Key words: molecular markers; ISSR marker; gamma ray.

$\left({ }^{1}\right)$ Recebido para publicação em 16 de dezembro de 2004 e aceito em 16 de novembro de 2005.

$\left(^{2}\right)$ Engenheiro Agrônomo, Doutorando do Programa de Pós-graduação em Agronomia FAEM/UFPel, Área de Concentração em Fitomelhoramento.

$\left(^{3}\right)$ Embrapa Clima Temperado, BR 392, km 78, Caixa Postal 403, 96001-970 Pelotas (RS).

$\left({ }^{4}\right)$ Departamento de Fitotecnia, FAEM/UFPel, Faculdade de Agronomia Eliseu Maciel, Campus Universitário, UFPel, Caixa Postal 354, 96001-970 Pelotas (RS). E-mail: acostol@terra.com.br.

$\left({ }^{5}\right)$ Acadêmica do Curso de Agronomia, Estagiária do Centro de Genômica e Fitomelhoramento, FAEM/UFPel. 


\section{INTRODUÇÃO}

A aveia branca (Avena sativa L.) é um dos mais importantes cereais, ocupando, em nível mundial, o sexto lugar em produção. No Brasil, essa cultura vem aumentando de importância a cada ano, atingindo, em 2002, o quinto lugar entre os cereais em área plantada (257.229 ha), com uma produção de 372.117 t (FAOSTAт, 2003). É uma incontestável planta melhoradora do solo, podendo ser utilizada como forma de sucessão da lavoura de arroz irrigado, com o objetivo de manter o solo protegido.

Com a incorporação de resíduos culturais ao solo antes de novo plantio, há potencialmente, a desvantagem de que produtos fitotóxicos, oriundos do metabolismo do material orgânico incorporado, possam exercer efeitos negativos, limitando a germinação e o estabelecimento das plântulas (CAmArgo et al., 2001). Em solos de várzea, devido ao alagamento, ocorrem condições anaeróbicas, onde o problema se agrava, pois dada à baixa eficiência metabólica microbiana na conversão do carbono adicionado, ocorre a acumulação de compostos que afetam, de forma irreversível, a produtividade final das culturas estabelecidas nesse sistema (CAMARGO et al.,1995a; BRANCKER et al., 1996).

Dos numerosos compostos formados pelo metabolismo anaeróbico, destacam-se os ácidos orgânicos, especialmente os ácidos alifáticos de cadeia curta, como o acético, o propiônico e o butírico. Os efeitos tóxicos desses ácidos dependem do tipo e da concentração (RAo e MiKKELSEN, 1977a).

O tipo e a quantidade dos ácidos produzidos durante o processo, dependem, basicamente, da quantidade e qualidade do resíduo orgânico adicionado, da característica fermentativa da microbiota e das condições predominantes no solo (CAmargo et al., 1993a). A acumulação desses ácidos no solo afeta diretamente algumas culturas, principalmente pela inibição da respiração, levando à diminuição no alongamento radicular (CAMARGO et al., 1993b) e na absorção de nutrientes (RAO e Mikkelsen, 1977a, 1977b; CAMARgo et al., 1995b).

Para que o cultivo da aveia seja uma alternativa economicamente viável em solos de várzea se faz necessário a utilização de cultivares com tolerância aos principais ácidos orgânicos produzidos pela decomposição da matéria orgânica: ácido acético, butírico e propiônico. Assim, é necessário avaliar e/ ou gerar variabilidade nas populações existentes para as condições ambientais decorrentes desse estresse abiótico.
A técnica de indução de mutação por irradiação tem sido muito empregada em programas de melhoramento de plantas. A mutação por irradiação pode ser utilizada com o objetivo de modificar algumas características para que se tornem úteis ao homem. Alterações nos caracteres ciclo e estatura de planta foram verificadas em plantas de aveia após a indução de mutações com raios gama (Coimbra et al., 2004).

A detecção dos efeitos desses agentes mutagênicos pode ser obtida com mais precisão com emprego de marcadores moleculares, uma vez que, com o advento das técnicas modernas de biologia molecular, surgiram diversos métodos de detecção de polimorfismo genético diretamente ao nível de DNA. O maior interesse na aplicação dos marcadores genéticos no melhoramento vegetal é a esperança de estabelecer ligações entre os marcadores e os genes que controlam determinada característica (OLIVEIRA et al., 1996).

Os marcadores genéticos moleculares têm inúmeras vantagens, destacando-se o fato de não serem influenciados pelo ambiente e serem independentes do estágio da vida da planta, sendo uma poderosa ferramenta dos programas de melhoramento genético (ZietKiewicz et al., 1994). A escolha de uma técnica de marcador molecular depende de sua reprodutividade e simplicidade. Desde 1994, uma técnica de marcador molecular nova, chamada amplificação inter repetições de seqüência simples (ISSR - Inter Simple Sequence Repeats) está disponível (ZIETKIEWICZ et al., 1994). ISSRs são marcadores semiarbitrários, ampliados por PCR em presença de um oligonucleotídeo complementar para um microssatélite designado.

Como um marcador com base em PCR, o ISSR tem algumas vantagens quando comparado aos outros marcadores. A amplificação não requer informações de sucessão do genoma e de padrões altamente polimórficos (ZIETKIEWICZ et al., 1994). Cada faixa corresponde a uma seqüência de DNA delimitada por dois microssatélites invertidos. Também, as seqüências-alvo dos ISSRs são abundantes ao longo do genoma de eucariontes e evoluem rapidamente (FANG e RoOse, 1997; EsSELMAN et al., 1999). Então, ISSRs têm provado serem úteis dentro de populações de estudos genéticos, especialmente em detecção clonal, diversidade e revelação de indivíduos proximamente relacionados (SALIMATH et al., 1995; OliveIRA et al., 1996).

O objetivo deste trabalho foi determinar a dissimilaridade genética entre famílias mutantes $M_{3}$ e a cultivar UFRGS 14 de aveia previamente classificadas quanto à tolerância a ácidos orgânicos mediante a utilização de marcadores ISSR, e detectar regiões genômicas associadas ao caráter. 


\section{MATERIAL E MÉTODOS}

O trabalho foi realizado no Laboratório de Genômica do Centro de Genômica e Fitomelhoramento (CGF) da Faculdade de Agronomia "Eliseu Maciel", da Universidade Federal de Pelotas, Pelotas (RS), no período de janeiro a março de 2004.

As famílias mutantes $\left(\mathrm{M}_{3}\right)$ utilizadas pertencem ao banco de mutantes de aveia do CGF. A cultivar UFRGS 14 deu origem aos mutantes utilizados neste estudo, os quais foram obtidos por mutação induzida por irradiação com raios gama $\left({ }^{60} \mathrm{Co}\right)$ na dose de 400 Gy. Foram utilizadas 30 famílias $\mathrm{M}_{3}$ avaliadas em gerações $M_{1}$ e $M_{2}$ quanto às características morfológicas do sistema radicular e parte aérea (Tabela 1).
As famílias $\mathrm{M}_{3}$ e a cultivar UFRGS 14 foram avaliadas em sistema hidropônico por Kopp et al., (2005) e classificadas como tolerantes e sensíveis segundo sua resposta à toxicidade pelos ácidos acético, propiônico e butírico (Tabela 1). Após as avaliações morfológicas, a matéria verde da parte aérea das plantas avaliadas foram armazenadas a $-80^{\circ} \mathrm{C}$ para posterior extração de DNA e estudos genomicos. A extração de DNA genômico foi realizada utilizando um bulk de 10 plantas de cada família mutante e da cultivar UFRGS 14 não mutada. A extração foi realizada pelo método CTAB $2 \%$, como descrito por SAghai-Maroof (1984) e tratada com RNAse à concentração final de $10 \mathrm{mg} \mathrm{mL}^{-1}$ para remoção de possível contaminação com RNA. Após o tratamento com RNAse foi realizada uma lavagem com álcool $76 \%$ e acetato de sódio $200 \mathrm{mM}$.

Tabela 1. Características morfológicas e de tolerância aos ácidos orgânicos das famílias $M_{3}$ mutantes utilizados no estudo de dissimilaridade genética. Pelotas-RS, 2004

\begin{tabular}{|c|c|c|c|c|c|}
\hline \multicolumn{2}{|c|}{ Genótipo } & \multirow{2}{*}{$\begin{array}{l}\text { Característica } \\
\mathrm{M}_{3} 2 \text { - Ausência de raízes seminais }\end{array}$} & \multicolumn{2}{|c|}{ Genótipo } & \multirow{2}{*}{$\begin{array}{l}\text { Característica } \\
\mathrm{M}_{3} 139 \text { - Ausência de raízes seminais e } \\
\text { raiz principal pilosa }\end{array}$} \\
\hline 1 & $\mathrm{~T}^{(1)}$ & & 17 & $S^{(2)}$ & \\
\hline 2 & $\mathrm{~T}$ & $M_{3} 9-$ Ausência de raízes seminais & 18 & S & $\mathrm{M}_{3} 178$ - Ausência de raízes seminais \\
\hline 3 & S & $M_{3} 10$ - Ausência de raízes seminais & 19 & S & M 183 - 3 Raízes seminais \\
\hline 4 & $\mathrm{~T}$ & $\begin{array}{l}M_{3} 17 \text { - Pilosidade acentuada na } \\
\text { raiz principal }\end{array}$ & 20 & S & $M_{3} 192$ - Ausência de raízes seminais \\
\hline 5 & S & $\begin{array}{l}\mathrm{M}_{3} 29 \text { - Presença de nódulos no } \\
\text { sistema de raízes }\end{array}$ & 21 & S & $\mathrm{M}_{3} 232$ - 3 Raízes seminais \\
\hline 6 & S & $\mathrm{M}_{3} 31$ - 3 Raízes seminais & 22 & S & $\mathrm{M}_{3} 244$ - 3 Raízes seminais \\
\hline 7 & $\mathrm{~T}$ & $\begin{array}{l}\mathrm{M}_{3} 40 \text { - Raiz principal com excesso } \\
\text { de raízes secundárias }\end{array}$ & 23 & $\mathrm{~T}$ & $\mathrm{M}_{3} 245$ - 3 Raízes seminais \\
\hline 8 & S & $\begin{array}{l}\mathrm{M}_{3} 41 \text { - Raiz principal com excesso } 24 \\
\text { de raízes secundárias }\end{array}$ & & S & $\mathrm{M}_{3} 286$ - 3 Raízes seminais \\
\hline 9 & S & $\begin{array}{l}\mathrm{M}_{3} 46 \text { - Raiz principal com excesso } \\
\text { de raízes secundárias }\end{array}$ & 25 & $\mathrm{~T}$ & M 307 - 3 Raízes seminais \\
\hline 10 & S & $\begin{array}{l}\mathrm{M}_{3} 50 \text { - Crescimento desuniforme } \\
\text { do sistema de raízes }\end{array}$ & 26 & S & $\mathrm{M}_{3} 308$ - 3 Raízes seminais \\
\hline 11 & $\mathrm{~T}$ & M 55 - 3 Raízes seminais & 27 & S & M 309 - 3 Raízes seminais \\
\hline 12 & $\mathrm{~S}$ & $\mathrm{M}_{3} 57$ - Engrossamento da raiz principal & 28 & $\mathrm{~S}$ & $\mathrm{M}_{3} 700$ - Folha bandeira larga \\
\hline 13 & S & $M_{3} 62$ - Sistema de raízes pouco desenvolvido & 29 & $\mathrm{~S}$ & $\mathrm{M}_{3} 701$ - Tardio \\
\hline 14 & S & $\mathrm{M}_{3} 73$ - 3 Raízes seminais & 30 & $\mathrm{~S}$ & $\mathrm{M}_{3} 702$ - Precoce \\
\hline 15 & S & $\mathrm{M}_{3} 130$ - 3 Raízes seminais & 31 & S & UFRGS 14 \\
\hline 16 & S & $\mathrm{M}_{3} 133$ - 3 Raízes seminais & - & - & - \\
\hline
\end{tabular}

$\left({ }^{1}\right) \mathrm{T}=$ Tolerante aos ácidos orgânicos. $\left({ }^{2}\right) \mathrm{S}=$ Sensível aos ácidos orgânicos. 
O DNA genômico foi visualizado em gel de agarose a $1 \%$, colorido com brometo de etídio incorporado ao gel na concentração de 5 ìg mL $\mathrm{mL}^{-1}$ para quantificação. A concentração do DNA foi ajustada para $50 \mathrm{ng} \mathrm{mL}^{-1}$ utilizando TE $\mathrm{pH} 8,0$.

A técnica molecular de marcadores ISSR foi utilizada, amplificando os fragmentos de acordo com BORNET e BRANCHARD (2001). Os fragmentos foram submetidos à eletroforese em cuba vertical com gel desnaturante de poliacrilamida $6 \%$ para separação. Os fragmentos foram visualizados, usando nitrato de prata, segundo CRESTE et al. (2001).

Foram testados 55 oligonucleotídeos, dos quais selecionaram-se 18 (UBC 811, 812, 823, 826, 829, 836, 841, $842,845,850,851,854,855,856,885,889,890,899)$, de acordo com a consistência dos marcadores (Tabela 4).

Os dados de CR foram submetidos à análise de variância, e regressão onde foi utilizado o programa computacional SAS LEARNING EDITION (2002).

Para os dados binários obtidos dos escores do gel, foi realizado o cálculo da taxa de mutação em relação a cultivar UFRGS 14 para cada oligonucleotídeo (Li e GE, 2001). A seguir foi estabelecida uma matriz de similaridade (DICE), utilizada para construção de um dendrograma pelo modelo Unweigthed Pair Group Method Arithmetic Average (UPGMA), em que também foi realizado o cálculo do coeficiente de correlação cofenética (r) (SOKAl e Rohlf 1962), sendo executados com auxílio do programa NTSYS-pc versão 1.8 (RoHLF, 2000). A análise de bootstraping, com 2.000 re-amostragens, foi efetuada utilizando-se o pacote computacional Winboot (Yap e Nelson, 1996).

\section{RESULTADOS E DISCUSSÃO}

O comportamento de cada família mutante e da cultivar UFRGS 14 não mutada foi previamente estudado (Kopp et al., 2005), que classificou morfologicamente quanto à tolerância ou sensibilidade aos ácidos orgânicos (Tabela 1). Tornase importante ressaltar que a cultivar UFRGS 14 não mutada é uma linhagem pura e sensível à toxicidade por ácidos orgânicos. Das 30 famílias mutantes estudadas, sete têm comportamento tolerante, enquanto as demais, comportamento sensível à toxicidade por ácidos orgânicos.

O padrão de bandas obtidos pela técnica ISSR permitiu identificar o total de 880 marcadores, dos quais 195 são polimórficos para 18 oligonucleotídeos, sendo obtidas médias de 48,9 marcadores totais e 10,8 marcadores polimórficos, respectivamente. Esses resultados concordam com os obtidos por Li e GE (2001), que verificaram 122 bandas polimórficas para 12 oligonucleotídeos avaliados. Desse total de bandas polimórficas, 74 estão ausentes na cultivar UFRGS 14 e presentes em algumas das famílias mutantes avaliadas. Dos outros 121 marcadores polimórficos, todos estiveram presentes na cultivar e ausentes em algumas das famílias testadas.

Os oligonucleotídeos UBC 854, 855 e 811 têm marcadores exclusivos em famílias tolerantes, podendo estar associados à tolerância à toxicidade por ácidos orgânicos. Nos oligonucleotídeos UBC 850 e 826, observaram-se marcadores com ausência somente em famílias tolerantes, podendo estar associados à sensibilidade aos ácidos.

Na Tabela 2 são apresentados os resultados referentes ao nível de polimorfismo das famílias $\mathrm{M}_{3}$ em relação à cultivar UFRGS 14 (não mutada) para cada oligonucleotídeo, sendo o valor médio verificado para todos os oligonucleotídeos de 32,79\%. Li e GE (2001), avaliando o percentual de bandas polimórficas em populações clonais que acumularam mutações naturais, notaram 2,33\%, mostrando que a mutação induzida ampliou em aproximadamente dez vezes esse valor.

Os oligonucleotídeos UBC 811, 826, 829, 856, 889 e 890 mostraram elevado grau de polimorfismo para as famílias em relação à cultivar UFRGS 14 . Desses, apenas no 811 ( $51,46 \%$ de polimorfismo) observou-se marcadores relacionados com a tolerância, indicando ser esse oligonucleotídeo potencialmente o mais indicado dentre os testados para acessar regiões genômicas mutadas e relacionadas ao caráter em estudo. O oligonucleotídeo UBC 826 foi também indicado para acessar regiões genômicas mutadas, porém, relacionadas à sensibilidade aos ácidos orgânicos.

Nos oligonucleotídeos UBC 823, 836, 850, 851, $854,855,885$ e 899 observou-se um nível de polimorfismo abaixo da média $(32,70 \%)$, revelando que foram acessadas regiões genômicas pouco mutadas, não devendo ser utilizados para detectar o nível de mutação induzida para as famílias testadas.

O dendrograma apresentou $\mathrm{r}=83 \%$ de semelhança com a matriz de similaridade (Dice, 1945). A similaridade genética observada entre as 30 famílias mutantes e a cultivar UFRGS 14 variou em distância, entre 0,88 e 0,60 , com a distância mínima entre as famílias 19 e 20 . 
Tabela 2. Nível de polimorfismo para cada oligonucleotídeo em relação a cultivar UFRGS 14. Pelotas-RS, 2004

\begin{tabular}{|c|c|c|c|c|}
\hline oligonucleotídeos & Seqüência & Médias & Máxima & Mínima \\
\hline UBC-811 & GAG AGA GAG AGA GAG AC & 51,46 & 86,67 & 3,33 \\
\hline UBC-812 & GAG AGA GAG AGA GAG AA & 33,67 & 70,00 & 6,67 \\
\hline UBC-823 & ТСТ СТС ТСТ СТС ТСТ СС & 27,62 & 63,33 & 6,67 \\
\hline UBC- -826 & ACA CAC ACA CAC ACA CC & 43,33 & 83,33 & 6,67 \\
\hline UBC- -829 & TGT GTG TGT GTG TGT GC & 45,95 & 90,00 & 6,67 \\
\hline UBC-836 & AGA GAG AGA GAG AGA GYA & 25,11 & 83,33 & 3,33 \\
\hline UBC- 841 & AGA GAG AGA GAG AGA AYC & 32,12 & 86,67 & 3,33 \\
\hline UBC- 842 & AGA GAG AGA GAG AGA AYG & 35,00 & 86,67 & 6,67 \\
\hline $\mathrm{UBC}-845$ & СТC TCT CTC TCT CTC TRG & 36,67 & 90,00 & 3,33 \\
\hline UBC- -850 & GTG TGT GTG TGT GTG TYC & 5,00 & 6,67 & 3,33 \\
\hline UBC- -851 & GTG TGT GTG TGT GTG TYG & 10,00 & 10,00 & 10,00 \\
\hline UBC- -854 & TCT CTC TCT CTC TCT CRG & 25,83 & 86,67 & 3,33 \\
\hline UBC- -855 & ACA CAC ACA CAC ACA CYT & 15,09 & 36,67 & 3,33 \\
\hline UBC-856 & ACA CAC ACA CAC ACA CYA & 51,43 & 63,33 & 10,00 \\
\hline UBC- 885 & BHB GAG AGA GAG AGA GA & 27,67 & 80,00 & 3,33 \\
\hline UBC- -889 & DBD ACA CAC ACA CAC AC & 48,89 & 86,67 & 6,67 \\
\hline UBC- 890 & VHV GTG TGT GTG TGT GT & 57,78 & 86,67 & 26,67 \\
\hline UBC-899 & CAT GGT GTT GGT CAT TGT TCC A & 17,65 & 63,33 & 3,33 \\
\hline Total & - & 32,79 & - & - \\
\hline
\end{tabular}

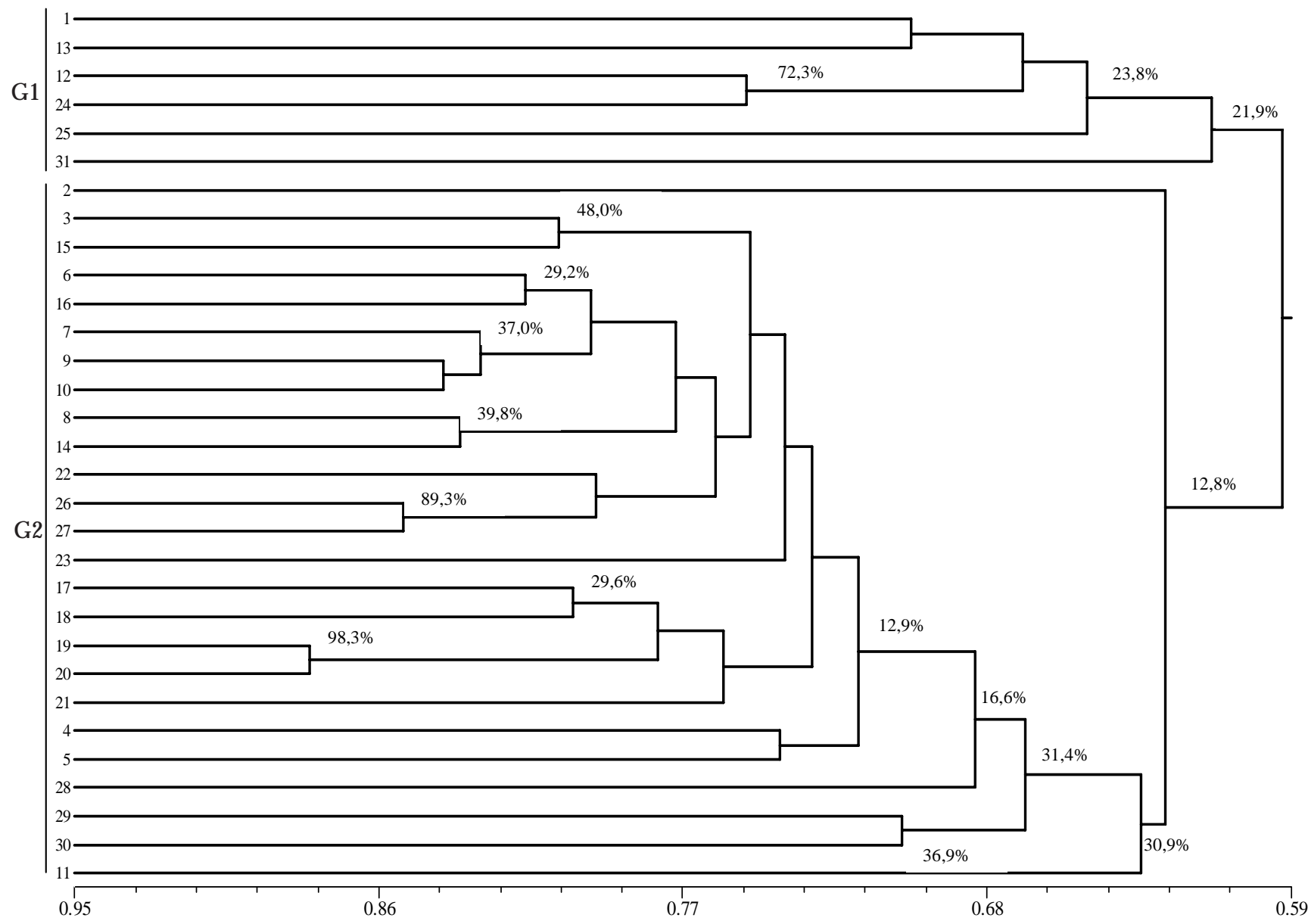

Figura 1. Dendrograma de 31 genótipos de aveia obtido a partir da análise de ISSR, utilizando o índice de similaridade de Dice (1945) e o método de agrupamento UPGMA. Os valores encontrados nos grupos indicam o valor percentual de vezes que os genótipos agruparam juntos em 2.000 ciclos de análise de bootstraping, utilizando o programa Winboot. O valor do coeficiente de correlação cofenética (r) é de 0,83. Pelotas-RS, 2004. 
Pode-se observar a separação das famílias em dois grandes grupos com similaridade média de aproximadamente 0,60 . As famílias tolerantes e sensíveis não permaneceram necessariamente nos mesmos agrupamentos, o que pode ser devido à aleatoriedade de grande número de regiões genômicas acessadas pelos oligonucleotídeos.

Como pode ser visto na Figura 1, o grupo 1 (G1) foi constituído pela cultivar UFRGS-14 e pelas famílias 13, 12, 24, 25 e 31. Dentro desse grupo estão as famílias com os menores índices de mutação, que se mantiveram no mesmo grupo da cultivar UFRGS 14. Como nesse grupo o nível de mutação detectada foi baixo, possivelmente as famílias tolerantes 12 e 24 , que se agruparam $72,3 \%$ das vezes em 2.000 reamostragens pelo Bootstraping (YAP e NeLSON, 1996), sofreram poucas mutações não associadas às regiões de interesse.

O grupo 2 (G2) foi constituído por maior número de famílias (25 famílias), com maior polimorfismo, formando um grupo diferenciado do grupo da cultivar UFRGS 14 (Figura 1). Nesse grupo constam famílias tolerantes e sensíveis, sugerindo que o aumento no número de mutações corresponde a um maior número de mutações não associadas ao caráter.

\section{CONCLUSÕES}

1. A técnica de ISSR revelou um índice de $32,70 \%$ de polimorfismo nas regiões genômicas acessadas entre a cultivar UFRGS 14 e famílias mutantes derivadas; e, dentre as 30 famílias, duas tolerantes classificaram-se no mesmo grupo da cultivar UFRGS 14 (sensível), com baixa mutação, porém efetiva para tolerância a ácidos orgânicos.

2. Os oligonucleotídeos UBC 854, 855 e 811 permitiram detectar regiões genômicas potencialmente associadas a tolerância à ácidos orgânicos, enquanto UBC 850 e 826 possibilitaram a identificação de regiões genômicas potencialmente associadas à sensibilidade.

\section{REFERÊNCIAS}

BORNET, B.; BRANCHARD, M. Nonanchored inter simple sequence repeat (ISSR) markers: Reproducible and specific tools for genome fingerprinting. Plant Molecular Biology Reporter, Georgia, v.19, p.209-215, 2001.

BRANCKER, A.; CAMARGO, F.A.O.; SANTOS, G.A. Occurrence of physiological disease in flooded rice fields. Ciência Rural, Santa Maria, v.26, n.1, p.149-151, 1996.
CAMARGO, C.E.O.; FERREIRA, A.W.P. Tolerância de cultivares de trigo a diferentes níveis de manganês em solução nutritiva. Pesquisa Agropecuária Brasileira, Brasília, v.27, n.3, p.417-422, 1992.

CAMARGO, O.C.E.; OLIVEIRA, O.F. Tolerância de cultivares de trigo níveis de alumínio em solução nutritiva e no solo. Bragantia, Campinas. v.49, p.21-23, 1981.

CAMARGO, F.A.; ZONTA, E.; SANTOS, G.A.; ROSSIELO, R.O.P. Aspectos fisiológicos e caracterização de toxidez a ácidos orgânicos voláteis em plantas. Ciência Rural, Santa Maria, v.31, n.3, p.523-529, 2001.

CAMARGO, F.A.O.; SANTOS, G.A.; ROSSIELLO, R.O.P. Acúmulo de nutrientes pelo arroz influenciado pela incorporação de palha em gleissolo. Revista Brasileira de Ciência do Solo, Campinas, v.19, n.2, p.243-247, 1995b.

CAMARGO, F.A.O.; SANTOS, G.A.; ROSSIELLO, R.O.P. Efeito dos ácidos acético e butírico sobre o crescimento de plântulas de arroz. Pesquisa Agropecuária Brasileira, Brasília, v.28, n.9, p.1011-1018, 1993b.

CAMARGO, F.A.O.; SANTOS, G.A.; ROSSIELLO, R.O.P. Incorporação de palha de arroz em um gleissolo e efeitos no rendimento da cultura do arroz irrigado. Pesquisa Agropecuária Brasileira, Brasília, v.30, n.7, p.983-987, 1995a.

CAMARGO, F.A.O.; SANTOS, G.A.; ROSSIELLO, R.O.P. Produção de ácidos orgânicos voláteis pela planta de arroz sob condições anaeróbicas. Revista Brasileira de Ciência do Solo, Campinas, v.17, n.3, p.337-342, 1993a.

COIMBRA, J.L.M.; CARVALHO, F.I.F.; OLIVEIRA, A.C. Genetic variability in populations of oat induced by chemical and physical mutagenic agents. Crop Breeding And Applied Biotechnology, Viçosa, v.4, p.48-56, 2004.

CRESTE, S.; TULMANN-NETO, A.; FIGUEIRA, A. Detection of single repeat polymorphism in denaturing polyacrylamide sequencing gels by silver staining. Plant Molecular Reporter, Georgia, v.19, p.1-8, 2001.

DICE, L.R. Measures of the amount of ecological association between species. Ecology, Washington, v.26, n.3, p.297-307, 1945.

ESSELMAN, E.J.; JIANQIANG, L; CRAWFORD, D.J.; WINDUSS, J.L.; WOLFE, A.D. Clonal diversity in the rare Calamagrostis porteri ssp. Insperata (Poaceae): comparative results for allozymes and random amplified polymorphic DNA (RAPD) and inter simple sequence repeat (ISSR) markers. Molecular Ecology, Edinburgh, v.8, p.443-451, 1999.

FANG, D.Q.; ROOSE, M.L. Identication of closely related citrus cultivars with inter-simple sequence repeat markers. Theoretical and Applied Genetics, New York, v.95, p.408417, 1997.

FAOSTAT Database Results. Disponível em: http:// www.fao.org/. Acesso em 10 de outubro de 2003. 
KOPP, M.M.; COIMBRA, J.L.M.; LUZ, V.K.; SOUSA, R.O.; CARVALHO, F.I.F.; OLIVEIRA, A.C. Tolerância a ácidos orgânicos em famílias mutantes $\mathrm{M}_{3}$ de aveia. Crop Breeding And Applied Biotechnology, Viçosa, 2005. (Prelo).

LI, A.; GE, S. Genetic variation and clonal diversity of Psammochloa villosa (Poaceae) detected by ISSR markers. Annals of Botany, London, v.87, p.585-590, 2001.

OLIVEIRA, A.C.; RICHTER, T.; BENNETZEN, J. L. Regional and racial specificities in sorghum germplasm assessed with DNA markers. Genome, Canada, v.39, p.579-587, 1996.

RAO, D.N.; MIKKELSEN, D.S. Effect of acetic, propionic, and butyric acids on young rice seedlings growth. Agronomy Journal, Madison, v.69, n.6, p.923-928, 1977a.

RAO, D.N.; MIKKELSEN, D.S. Effects of acetic, propionic, and butyric acids on rice seedlings growth and nutrition. Plant and Soil, The Hague, v.47, p.323-334, 1977b.

ROHLF, F.J. NTSYS-pc: numerical taxonomy and multivariate analysis system, version 2.1. New York: Exeter Software, 2000.

SAGHAI-MAROOF, M.A.; SOLIMAN, K.M.; JORGENSEN, R.A.; ALLARD, R.W. Ribosomal DNA spacer length polymorphism in barley: Mendelian inheritance, chromosome location and population dynamics. Proceedings of the National Academy of Sciences of the U.S.A., Washington, v.89, n.2, p.1477-1481, 1984.
SALIMATH, S. S.; OLIVEIRA, A.C.; GODWIN, I.O.A.C.; BENNETZEN, J.L. Assessment of genome origins and genetic diversity in the genus eleusine with DNA markers. Genome, Canada, v.38, p.757-763, 1995.

SAS LEARNING EDITION. Getting Started with the SAS Learning Edition, Care, North Carolina: SAS Institute Inc., 2002.

SOKAL, R.R.; ROHLF, F.J. The comparison of dendrograms by objective methods. Táxon, Berlin, v.11, n.1, p.30-40, 1962

SOUSA, R.O.; BORTOLON, L. Crescimento radicular e da parte aérea do arroz (Oryza sativa L.) e absorção de nutrientes em solução nutritiva com diferentes concentrações de ácido acético. Revista Brasileira de Agrociência, Pelotas, v.8, n.3, p.231-235, 2002.

YAP, I.V.; NELSON, R.J. Winboot: a program for performing bootstrap analysis of binary data to determine the confidence limits of UPGMA-based dendrograms. Manila: IRRI, 1996. 22p.

ZIETKIEWICZ, E.; RAFALSKI, A.; LABUDA, D. Genome Fingerprinting by simple sequence repeat (SSR)-anchored polymerase chain reaction amplification. Genomics, San Diego, v.20, p.176-183, 1994. 